\title{
Study and Design of an Application for Measuring the Harmful Character of Computer Equipment and Telecommunications
}

\author{
Ayaovi Agbétoméfa Kpeto ${ }^{1,2}$, Eyouléki Tcheyi Gnadi Palanga ${ }^{2}$, Koffi Sagna ${ }^{1, *}$, \\ Komi Apélété Amou ${ }^{1}$, Koffi-Sa Bédja ${ }^{2}$ \\ ${ }^{1}$ Laboratory on Solar Energy, Physics Department, Sciences Faculty, University of Lomé, Lomé, Togo \\ ${ }^{2}$ Computer and Computing Center, Option: Systems and Networks Research Laboratory ENSI, University of Lomé, Lomé, Togo
}

Email address:

ksagna@univ-lome.tg (K. Sagna)

${ }^{*}$ Corresponding author

\section{To cite this article:}

Ayaovi Agbétoméfa Kpeto, Eyouléki Tcheyi Gnadi Palanga, Koffi Sagna, Komi Apélété Amou, Koffi-Sa Bédja. Study and Design of an Application for Measuring the Harmful Character of Computer Equipment and Telecommunications. American Journal of Energy Engineering. Vol. 7, No. 1, 2019, pp. 8-14. doi: 10.11648/j.ajee.20190701.12

Received: July 31, 2018; Accepted: August 14, 2018; Published: April 7, 2019

\begin{abstract}
The office electrical, computer or telecom equipment we use on a daily basis emits electromagnetic waves. These waves would have long-term and short-term effects on the human body. Since the direct proofs of cause and effect are still insufficient, a measurement study will be made of these materials in order to know the value of the magnetic field that each of them emits. A discussion of these values against standards' will lead to the design of a NOCIONDE (application revealing HARMfulness of the WAVEs if it exists). Based on the precautionary principle, NOCIONDE is a web application or a tool for measuring the harmful nature of materials that offers recommendations to users to follow so that they will not be victimized one day if the evidence proves to be true. The aim of this study is to show the harmful character of computer equipment and telecommunications trough the measuring of the electromagnetic field values compared to the standard required by the World Health Organization. The materials' classification is obtained. In addition, the results of NOCIONDE reveal clearly that the provisions concerning the telephone and other equipment emitting radio waves should be respected.
\end{abstract}

Keywords: Electromagnetic Waves, Magnetic Field, Standards' Values, Nocionde

\section{Introduction}

Humans impact the environment in several ways. Electromagnetic waves play an important role in all areas of our life. Especially the use of radio, television, other electronic materials and cellular systems that come out as a result of technological developments has expanded rapidly. This is a part of one of the causes of environmental pollution. Just as the environmental pollution due to the exhaust gases of engines in operation demonstrated by the work of Koffi Sagna et al. [1]. Environmental pollution due to the propagation of electromagnetic waves has become a major concern not to be neglected though this pollution is invisible.

The purpose of this study is to help anyone to go to the precautionary principle to guard against any possible harmful effects of electromagnetic waves emitted by computer and telecommunications equipment. Research has shown that these waves will result in biological effects and effects due to their overexposure [2-4]. The worry today concerns the effects due to the overexposure of the extremely low frequency and radiofrequency radiation emitted by these materials $[5,6]$. These last ones would be sources of the incurable diseases, but until today it is difficult to establish a link cause and effect between these diseases and the overexposure to these waves. Their harmfulness to human health remains uncertain. Following the results of epidemiological studies, in June 2002 exposure to extremely low frequency electromagnetic waves was classified in Category $2 \mathrm{~B}[7,8]$ by the International 
Agency for Research on Cancer (IARC) attached to the World Health Organization.

No further in May 2011, following a meta analysis, the same organization, classified the radio waves [9] in the same category. This 2B label means possibly carcinogenic. This means the risk is likely but research on its realization remains inconclusive. Thus, in the absence of rational explanations of the real impacts of the extremely low frequency and radiofrequency waves, the ICNIRP (International Commission on Non-Ionizing Radiation Protection) recommends the precautionary principle [10]. Starting from this principle, this article will be devoted to the comparative study of the value of the magnetic field emitted by each material in relation to the limit values of exposure. The measurement tool, the NOCIONDE application designed at the end of this study will incorporate this property of comparison for each time bring out recommendations for users.

\section{Measuring Device}

Measurements are made using a Teslameter called Gaussmeter Tesla meter WT10A WT-10A. It allows to get the value of the static magnetic field on the surface of a material. Still called fluxmeter, it also allows to measure the magnetic induction of the apparatus emitting the low waves extremely low frequencies or radiofrequencies. It is a portable instrument, which offers a wide range of measurement and easy to use. Thanks to its Ns function coupled with the metal probe, it plays the role of tester of the magnetic field. It has four (04) buttons. The first in red allows to turn it on and off. The second one in the middle, allows to adjust the device before any measurement. The third in yellow makes it possible to choose the range of measurements: 0-200 $\mathrm{mT}$ for small measurements and $200 \mathrm{mT}-2000 \mathrm{mT}$ for large mesurements. Its sensitivity is 0.1 $\mathrm{mT}$ and the accuracy margin is $+/-2 \%$.

\section{Experimental Protocol}

The purpose of this work is to see in which range of magnetic induction value or static magnetic field materials emit, then compare these values to standards recommended by international organisations. For this reason, a stock-taking in three steps has been made from material to material for an evaluation of their harmfulness.

\subsection{Step One: Hardware Approach}

The value of the magnetic field decreases as the distance increases. The first step will be to approach the device of the probe tesla meter. The maximum distance in our case is $3 \mathrm{~cm}$.

\subsection{Second Step: Passing the Probe on the Device}

It is not all parts of the material that emit electromagnetic radiation. For this purpose, we will pass the probe on the different parts of the device to detect the one that emits most. It is the part which will hold our attention. On this part, we will make three measurements that we will note V1, V2, V3.

\subsection{Step Three: Choosing the Best Measure}

The value to retain here will not be the average of the values taken. Of all the values, the one that will hold our attention will be the greatest value. The idea is to see the effect that each material has on human health.

Measurement will not be done in relation to a group of materials but in relation to each material, to a specific part.

\section{Results and Discussion}

The following points are the conclusions obtained by measuring the magnetic field emitted on the equipment, following the experimental protocol described above.

\subsection{Distance with Electromagnetic Wave Emission}

By approaching and removing the teslameter from the equipment during the measurements, we obtain a variation of the value of the magnetic induction presented in Table 1 below

Table 1. Magnetic induction versus distance.

\begin{tabular}{lll}
\hline \multirow{2}{*}{ Materials } & \multicolumn{2}{l}{ Values of magnetic induction in mT } \\
\cline { 2 - 3 } & At 3cm & At 5cm \\
\hline Mail server Proliant ML350 Gen9 & 0,6 & 0,4 \\
File Server Proliant intel DL & 0,2 & 0,1 \\
370G6 & 0,7 & 0,2 \\
Web server Proliant ML 350P Gen8 & 0,5 \\
Inverter Online Interactive UPS & 1,2 & 0,1 \\
Switch 1 Dlink DES 1024R+ & 0,3 & 0 \\
Switch 2 Catalyst 3500 Series & 0,2 & 0,5 \\
\hline
\end{tabular}

The characteristics of the magnetic field $\vec{B}$ depending on the type of material and the distance are shown in Figures 1 and 2 below and this in comparison with the short-term standard.

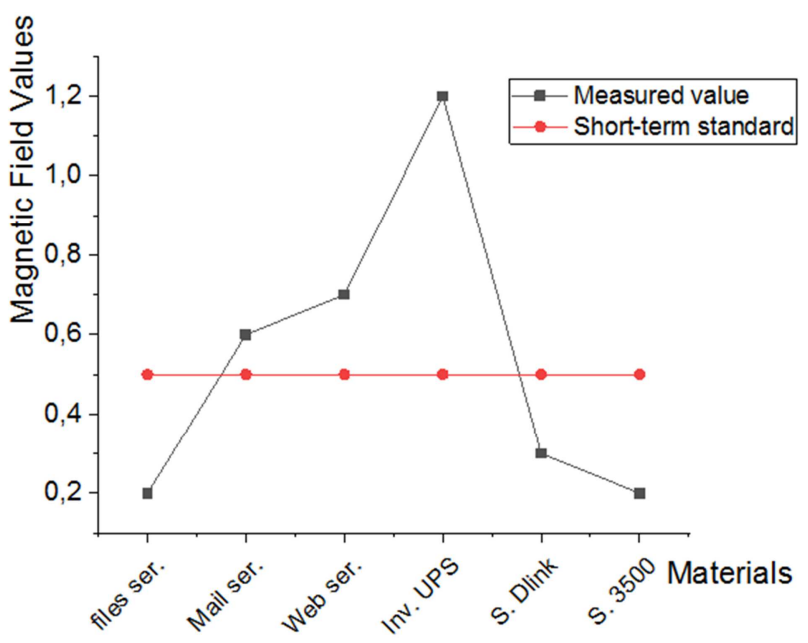

Figure 1. Exposure at $3 \mathrm{~cm}$. 


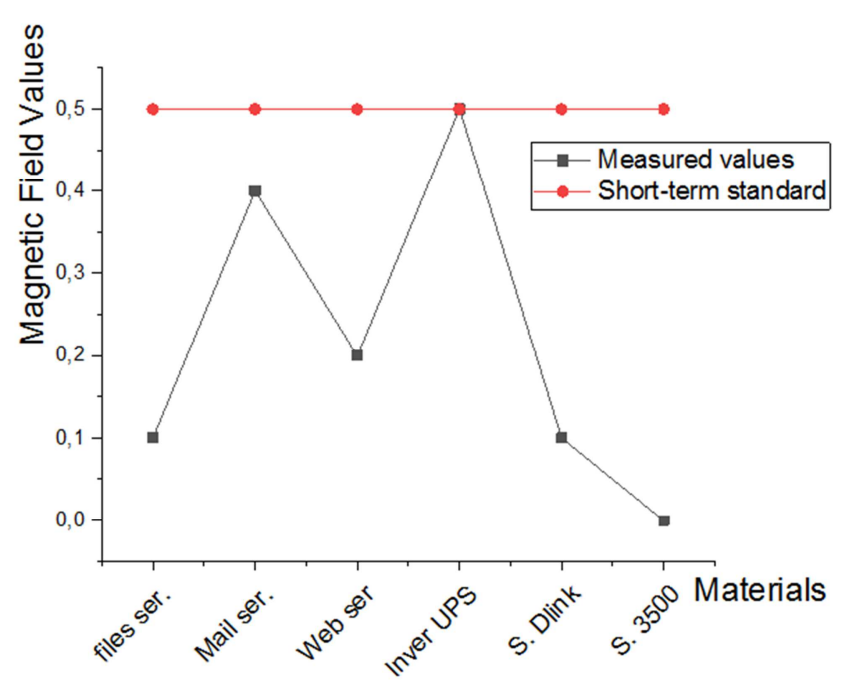

Figure 2. Exposure at $5 \mathrm{~cm}$.

We note from these two figures that the value of the magnetic induction decreases once one moves away from the material. The degree of harmfulness of a material would therefore decrease, when one moves away from this material. This confirms the results of the AFFSET in its report of collective expertise [11] that the value of the magnetic induction depends largely on the distance that one is in relation to a material.

\subsection{Permanent Presence of Waves in Server Rooms}

During the measurements, we found that a simple introduction of the teslameter in a server room without being approached to a material brings up a value on its screen. This is not the case when we enter the offices. A combination of these two approaches would better explain this remark.

a) Server room machines operate without interruption.
This permanent circulation of charges would therefore be the cause of a permanent magnetic field at the level of each material;

b) The promiscuity of computer equipment in the server rooms would also cause an increase in the magnetic field emission value at the level of each equipment. This would be an amplification of a physical phenomenon due to the fact that each of these devices emits at its level a magnetic field. Close to another, it will be subject to the magnetic field emitted by the latter which would induce an exaltation of the phenomenon to those around him. This confirms the work of O. Tardy, R. Lennuier in their study of the influence of a magnetic field on the intensity of the airs emitted by some discharge tubes [12].

\subsection{Influence of Voltage}

An observation made at the voltage level during the measurements is presented in Table 2 below.

Table 2. Magnetic induction values with the voltage.

\begin{tabular}{lll}
\hline Materials & Voltage in V & $\begin{array}{l}\text { Magnetic field values in } \\
\mathbf{m T}\end{array}$ \\
\hline $\begin{array}{l}\text { Inverter Online Interactive UPS } \\
\text { Interrupted Power Supply }\end{array}$ & $96 \mathrm{~V}$ & $\mathrm{~V}_{1}=1,2, \mathrm{~V}_{2}=0,9 ; \mathrm{V}_{3}=1$ \\
$\begin{array}{l}\text { Inverter APC Smart UPS } \\
\text { RT1000 }\end{array}$ & $12 \mathrm{~V}$ & $\mathrm{~V}_{1}=0,1 ; \mathrm{V}_{2}=0,1$ \\
Inverter EATMON 5E & $12 \mathrm{~V}$ & $\mathrm{~V}_{1}=0,2 ; \mathrm{V}_{2}=0,1 ; \mathrm{V}_{3}=0,2$ \\
\hline
\end{tabular}

The characteristics of the magnetic field $\vec{B}$ depending on the type of material and the distance are shown in Figure 3 below and this in comparison with the short-term standard.

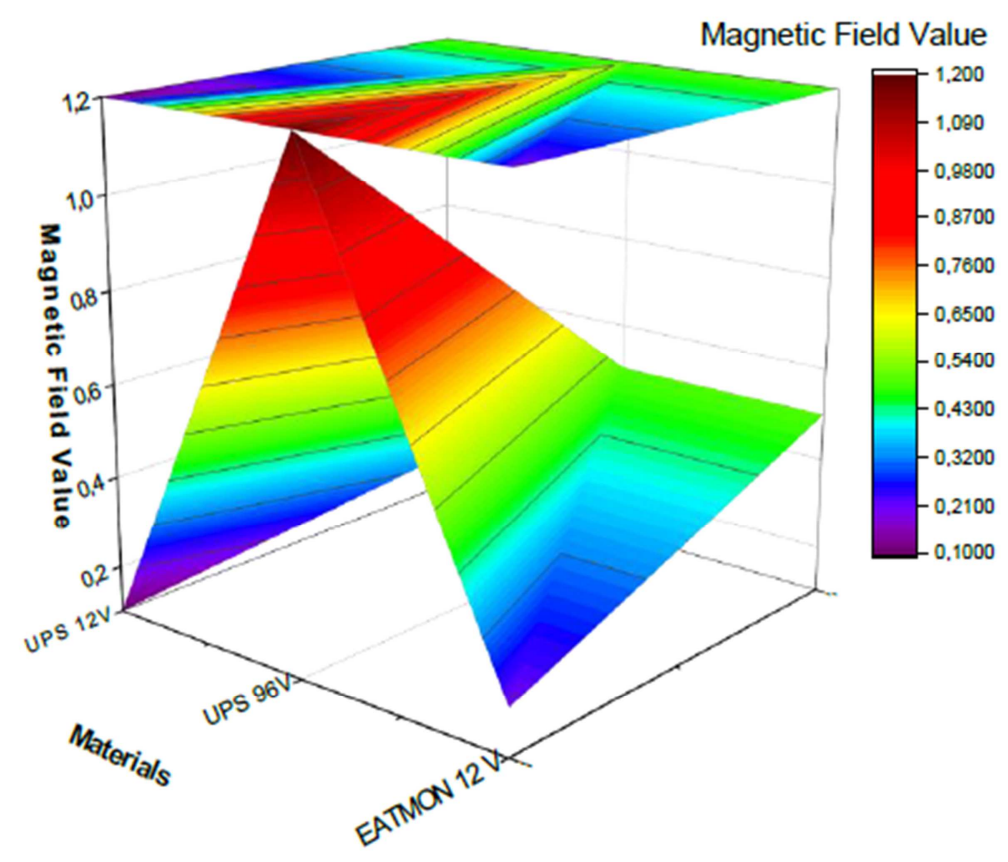

Figure 3. Influence of the voltage on the emission of the magnetic field. 
The result obtained shows that the value of the emitted magnetic field increases with the electric power. This confirms the work of A. RAGHI who in his article of Magnetic Field Influence on Current Intensity in Rarefied Air found that the transformation of cathodic rays into magnetic rays is accompanied by a very marked increase in the potential difference [13].

\subsection{Electronic Components Constituting the Material}

Measurements of the magnetic field values gave different values at the server level as shown in Table 3 below.

Table 3. Magnetic field values of the servers.

\begin{tabular}{lll}
\hline Servers & Brands & Magnetic field values in mT \\
\hline Files Server Proliant intel DL 370G6 & HP & $\mathrm{V}_{1}=0,1 ; \mathrm{V}_{2}=0,1 ; \mathrm{V}_{3}=0,2$ \\
Mail Server Proliant ML350 Gen9 & $\mathrm{HP}$ & $\mathrm{V}_{1}=0,6 ; \mathrm{V}_{2}=0,2 ; \mathrm{V}_{3}=0,3 ; \mathrm{V}_{4}=0,5$ \\
Web Server Proliant ML 350P Gen8 & $\mathrm{HP}$ & $\mathrm{V}_{1}=0,4 ; \mathrm{V}_{2}=0,7 ; \mathrm{V}_{3}=0,5$ \\
Digital Server Campus System x3650 M & IBM & $\mathrm{V}_{1}=0,1 ; \mathrm{V}_{2}=0,2 ; \mathrm{V}_{3}=0,2$ \\
Voice Server on IP & IBM & $\mathrm{V}_{1}=0,2 ; \mathrm{V}_{2}=0,1$ \\
S2ESup Server & IBM & $\mathrm{V}_{1}=0,2 ; \mathrm{V}_{2}=0,1$ \\
DNS Server intel Xeon CZ25491G03 & HP & $\mathrm{V}_{1}=0,4 ; \mathrm{V}_{2}=0,3 ; \mathrm{V}_{3}=0,8$ \\
\hline
\end{tabular}

The characteristics of the magnetic field $\vec{B}$ depending on the type of material and the distance are shown in Figure 4 below and this in comparison with the short-term standard.

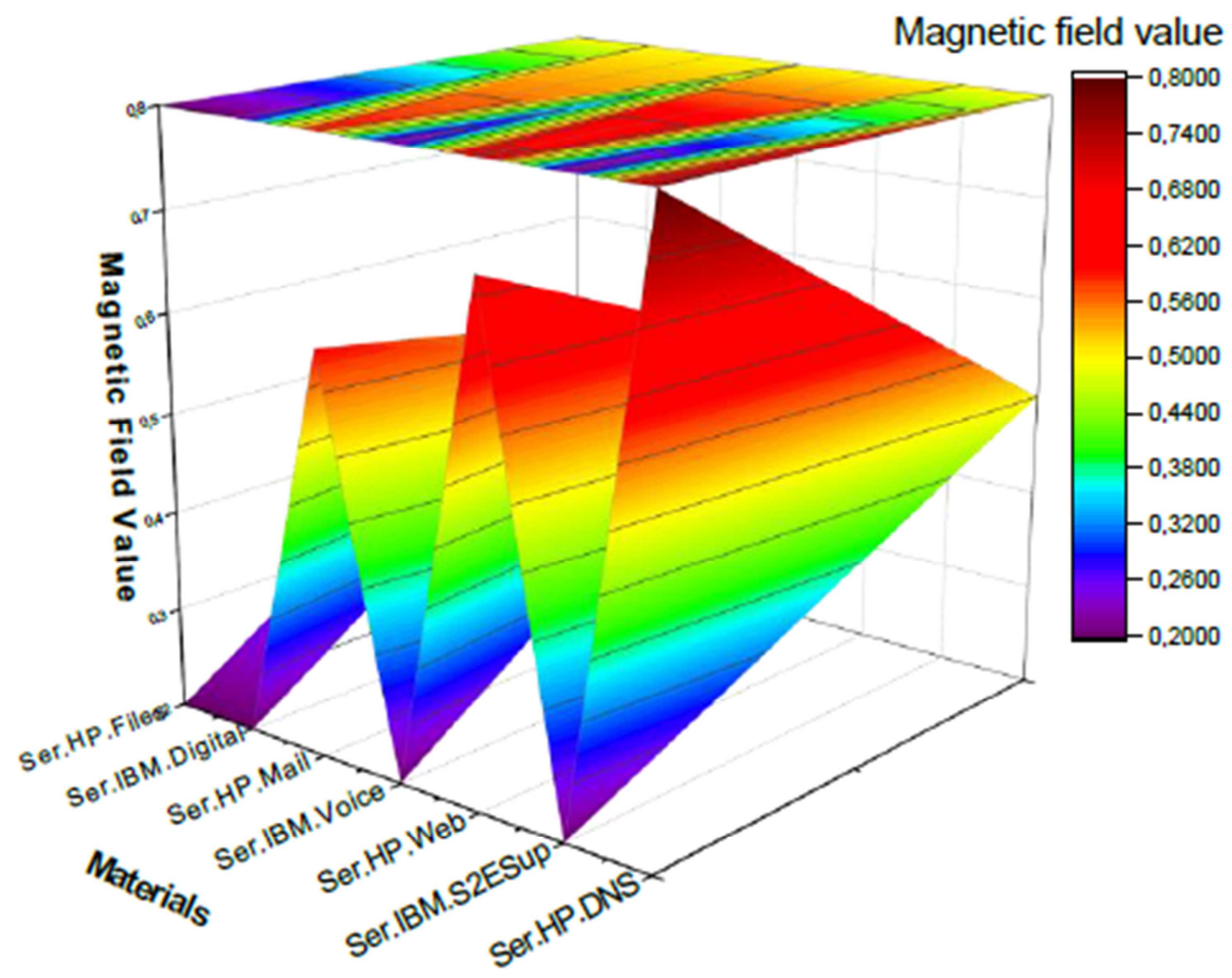

Figure 4. Magnetic induction based on computer servers.

From a physical point of view, these servers look similar. But, we notice a clear difference in their emitted magnetic field value, taken under the same conditions. The results we obtain, show that the electromagnetic field emission would vary from one brand to another. The emission of the electromagnetic wave of a server would therefore depend on the brand and the server model. This would come from the fact that certain equipment, considering their functions, would be designed with more sophisticated electronic components that consume much more energy, thus more electric energy. This would lead to a considerable emission of the electromagnetic wave. In other words, some brands of servers would be more harmful than others. This would partly confirm GUILLAUME GUERSAN's work on GreenIT [14].

\subsection{Telecommunications Equipment Would Be Harmful to the Human Body}

Measurements of the value of the magnetic field emitted, made on the various fixed and mobile telephones are shown in Table 4 below. 
Table 4. Field magnetic's values emitted by mobiles.

\begin{tabular}{lll}
\hline Telephones & Brands & Magnetic field's values \\
\hline \multirow{3}{*}{ Fixed } & Microtel Model KX-TSC880CID & $\mathrm{V}_{1}=5,2$ \\
& Gaoke HCD737TSDL59 & $\mathrm{V}_{1}=6,3$ \\
& Panasonic KX-TS840MXW & $\mathrm{V}_{2}=7,6$ \\
& Gaoke HCD737TSDL & $\mathrm{V}_{3}=6,6$ \\
& Itel it 1508 & $\mathrm{V}_{1}=8,2$ \\
Mobiles & Illico CAM Togotelecom & $\mathrm{V}_{1}=16,8$ \\
& Invens Royal R4 & $\mathrm{V}_{1}=4,1$ \\
& M. Wiko WiM & $\mathrm{V}_{1}=4,2$ \\
& Huawei & $\mathrm{V}_{1}=10,7$ \\
\hline
\end{tabular}

To know the level of harmfulness of these telephones to the human body, we will use the comparison relation: $\mathrm{M}^{2} / 6 \mathrm{x}$ $10^{-6} \leq \mu_{0}{ }^{2} \mathrm{H}_{\mathrm{NR}}{ }^{2}$.

If $\mathrm{M}^{2} / 6 \times 10^{-6} \leq \mu_{0}{ }^{2} \mathrm{H}_{\mathrm{NR}}{ }^{2}$ then the material is not harmful.

We will take $\mathrm{H}_{\mathrm{NR}}(\mathrm{A} / \mathrm{m})=0,008335 \mathrm{f}^{0,3417}$ according to the evaluation criteria of the magnetic field [15]. $\mathrm{f}$ being the transmission frequency, in this case we will take the GSM transmission frequency equal to $900 \mathrm{MHz}$. M et $\mu_{0}$ respectively represent the measurement of the magnetic field and the permeability in the vacuum.

$\mu_{0}=8,8541878210^{-12} \mathrm{~m}^{-3} \mathrm{~kg}^{-1} \mathrm{~s}^{4} \mathrm{~A}^{2}$. The using of these relations and expressions, give us the following table 5 .

Table 5. Harmfulness of phones.

\begin{tabular}{lll}
\hline Brands & Magnetic field's values & Harmfulness's verification $\mathbf{M}^{2} / \mathbf{6} \times \mathbf{~ 1 0}^{-6} \leq \boldsymbol{\mu}_{\mathbf{0}} \mathbf{2}_{\mathbf{N R}}{ }^{2}$ \\
\hline Microtel Model KX- TSC880CID & $\mathrm{V}_{1}=5,2$ & $(5,2)^{2} \times 10^{-6} / 6>\left(8,85418782 \times 10^{-12}\right)^{2}\left(0,008335900^{0,3417}\right)^{2}$ \\
Gaoke HCD737TSDL59 & $\mathrm{V}_{1}=6,3$ & $(6,3)^{2} \times 10^{-6} / 6>\left(8,85418782 \times 10^{-12}\right)^{2}\left(0,008335900^{0,3417}\right)^{2}$ \\
Panasonic KX-TS840MXW & $\mathrm{V}_{2}=7,6$ & $(7,6)^{2} \times 10^{-6} / 6>\left(8,85418782 \times 10^{-12}\right)^{2}\left(0,008335900^{0,3417}\right)^{2}$ \\
Gaoke HCD737TSDL & $\mathrm{V}_{3}=6,6$ & $(6,6)^{2} \times 10^{-6} / 6>\left(8,85418782 \times 10^{-12}\right)^{2}\left(0,008335900^{0,3417}\right)^{2}$ \\
Itel it 1508 & $\mathrm{V}_{1}=8,2$ & $(8,2)^{2} \times 10^{-6} / 6>\left(8,85418782 \times 10^{-12}\right)^{2}\left(0,008335900^{0,3417}\right)^{2}$ \\
Illico Togotelecom & $\mathrm{V}_{1}=16,8$ & $(16,8)^{2} \times 10^{-6} / 6>\left(8,85418782 \times 10^{-12}\right)^{2}\left(0,008335900^{0,3417}\right)^{2}$ \\
Invens Royal R4 & $\mathrm{V}_{1}=4,1$ & $(4,1)^{2} \times 10^{-6} / 6>\left(8,85418782 \times 10^{-12}\right)^{2}\left(0,008335900^{0,3417}\right)^{2}$ \\
M. Wiko WiM & $\mathrm{V}_{1}=4,2$ & $(4,2)^{2} \times 10^{-6} / 6>\left(8,85418782 \times 10^{-12}\right)^{2}\left(0,008335900^{0,3417}\right)^{2}$ \\
Huawei P9 Lite & $\mathrm{V}_{1}=10,7$ & $(10,7)^{2} \times 10^{-6} / 6>\left(8,85418782 \times 10^{-12}\right)^{2}\left(0,0083359000^{0,3417}\right)^{2}$ \\
\hline
\end{tabular}

The red color reminds us once how much the mobile phones we use would be harmful to humans and that precautions should be taken to better protect against any effect if it would exist.

\section{NOCIONDE Application}

NOCIONDE (HARMfulness of the WAVEs) is a Web application set up to see if the amount of an electromagnetic wave emitted by an electronic equipment is harmful to its user. It is an application designed with the Laravel
Framework and based on ICNIRP international standards. By a value input of the magnetic field measured on a material, NOCIONDE presents at the output, a result describing the harmfulness of the material joined to the recommendations. So according to the level of harmfulness we have:

a) The green color: The material would not be harmful;

b) The orange color: The material would be harmless;

c) Red color: the material would be harmful.

The Figure 1 shows the interface of the NOCIONDE application home page

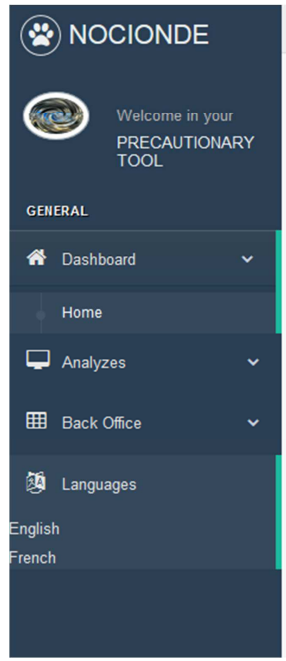

Analyze the electromagnetic emission of your equipment

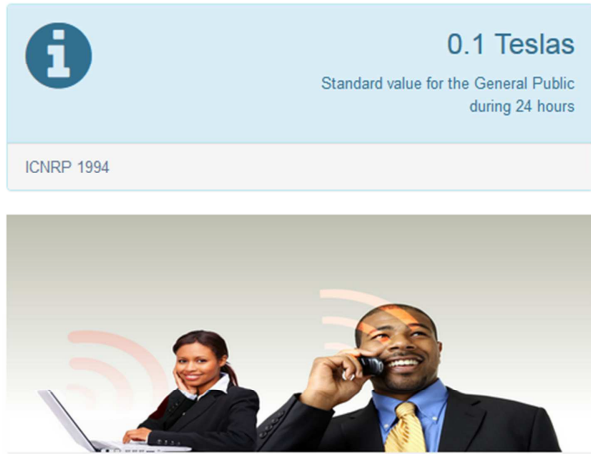

Figure 5. Home page.

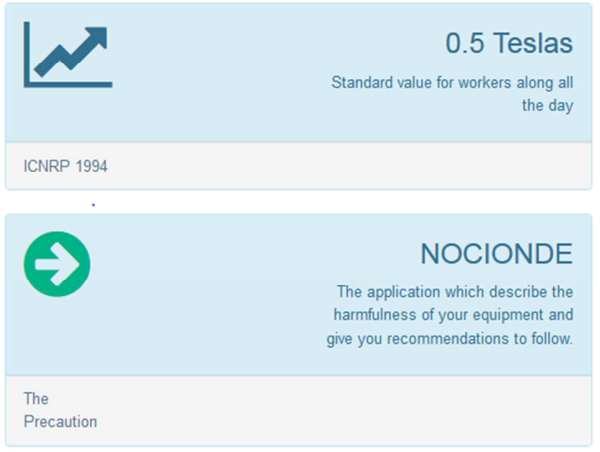


NOCIONDE offers essentially three (03) major functions:

a) Analysis of equipment emitting extremely low frequency electromagnetic waves;

b) Analysis of equipment emitting radiofrequency waves;

c) Research based on pre-performed analyzes.

V.1 Analysis of the equipment emitting the waves extremely low frequencies

The user on this page, must complete four (04) analysis criteria.

a) Material: At this level is several materials. The user will choose the material for which he wishes to analyze.

b) Value of the magnetic field $(\mathrm{mT})$ : it will be able to scroll to arrive at the value of the magnetic field emitted by the material or to put directly this value.

c) Exposure period and type of exposure: These last two criteria correspond to international standards.

Table 6. Short-Term exposure standards.

\begin{tabular}{lll}
\hline Target & $\begin{array}{l}\text { Exposure's } \\
\text { caracterization }\end{array}$ & $\begin{array}{l}\text { Exposure's standard } \\
\text { magnetic field in mT }\end{array}$ \\
\hline Workers & During the day & 0,5 \\
Public & During 24 hours & 0,1 \\
\hline
\end{tabular}
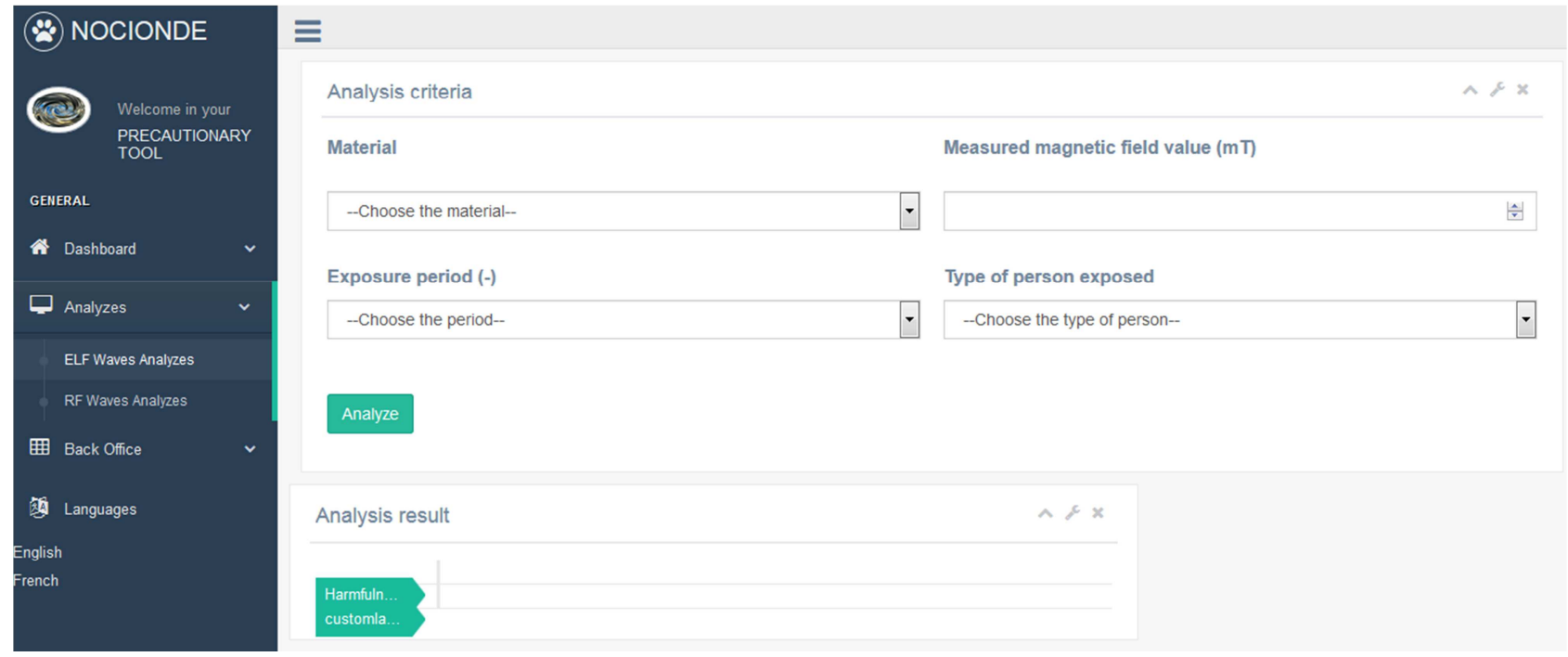

Figure 6. Analysis page of a material emitting an extremely low frequency wave.

V.2 Analysis of materials emitting radiofrequency waves

The user on this page must fulfill another criterion in addition to the five (05) primary evaluation criteria. This is the transmission frequency of the material to be analyzed.
This frequency is for example $900 \mathrm{MHz}$ for a phone emitting a single call, $1800 \mathrm{MHz}$ for a $3 \mathrm{G}$ connection, $2450 \mathrm{MHz}$ for a Wifi connection. The figure below shows the analysis interface.

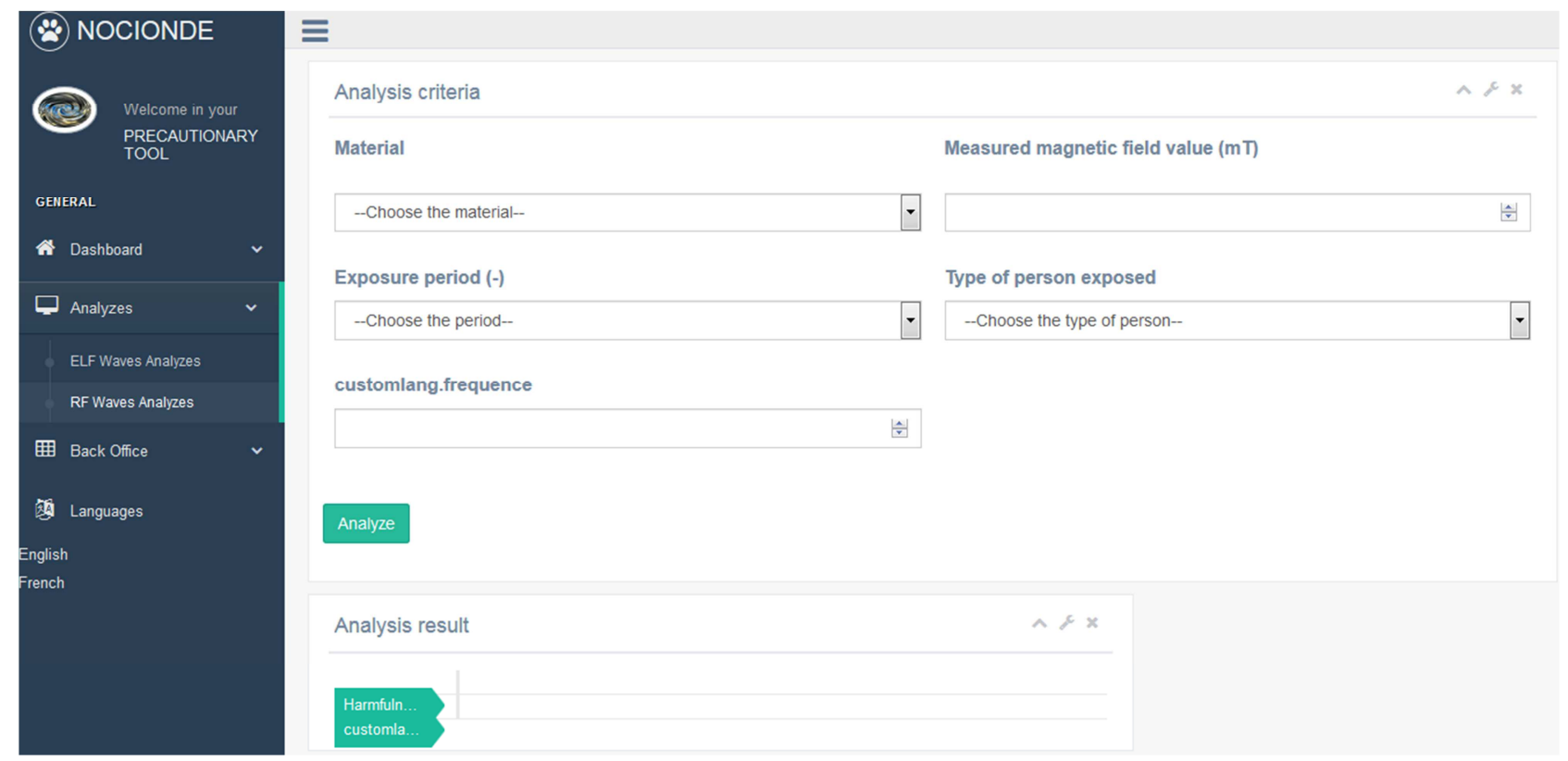

Figure 7. Analysis interface of a material emitting radio waves. 
V.3 Research based on pre-performed analyzes This is a help function for users who don't have teslameter or do'nt know how to use a teslameter. All they have to do is to enter the name of the material. The application NOCIONDE will do researches and show them the level of its harmfulness. NOCIONDE is today a tool adapted to any user and allows to go quickly to the principle of precaution.

\section{Conclusion}

A classification of materials against the short-term standard would therefore give, us:

a) Materials that would not be harmful: Displays, CPUs, inverters, printers, photocopiers;

b) Equipment that would be harmless: servers, inverters;

c) Materials that would be harmful: servers; laptops and cell phones.

Arrangements should be made today concerning the use of these materials since there is still uncertainty about their degree of harm. The application NOCIONDE, set up as a result of this work allows to go to the principle of precaution as advised by international organizations such as ICNIRP, WHO, IARC. It is an application based on the exposure limit values recommended by international standards and recommendations permitting to avoid the harmfulness of the waves. The materials studied emit extremely low frequency and radiofrequency waves. The operation behind this application is to compare these standard values to the measured values.

In addition, the results of this application reveal clearly that provisions concerning the telephone and other equipment emitting radio waves should be respected.

\section{References}

[1] Koffi Sagna, Komi Apélété Amou, Tchamye Tcha-Esso Boroze, Djima Kassegne, Amah d'Almeida, Kossi Napo. Environmental Pollution due to the Operation of Gasoline Engines: Exhaust Gas Law. International Journal of Oil, Gas and Coal Engineering. Special Issue: Computer-Aided Reservoir Characterization Methods. Vol. 5, No. 4, 2017, pp. 39-43. doi:10.11648/j.ogce.20170504.11.

[2] J. Dyche, A. M. Anch, K. A. J. Fogler, D. W. Barnett, and C. Thomas, "Effects of power frequency electromagnetic fields on melatonin and sleep in the rat," Emerging Health Threats Journal, Article ID 10904, pp. 1-8, 2012.

[3] S. Cucurachi, W. L. M. Tamis, M. G. Vijver, W. J. G. M. Peijnenburg, J. F. B. Bolte, and G. R. de Snoo, "A review of the ecological effects of radiofrequency electromagnetic fields (RF-EMF)," Environment International, vol. 51, pp. 116-140, 2013.

[4] B. Lewczuk, G. Redlarski, A. Żak, N. Ziółkowska, B.
Przybylska-Gornowicz, and M. Krawczuk, "Influence of electric, magnetic and electromagnetic fields on the circadian system-current stage of knowledge," BioMed Research International, vol. 2014, Article ID 169459, 13 pages, 2014.

[5] A. Ferikoglu, O. Cerezci, M. Kahriman, and S. C. Yener, "Electromagnetic absorption rate in a multilayer human tissue model exposed to base-station radiation using transmission line analysis," IEEE Antennas Wirel. Propag. Lett., vol. 13, pp. 903-906, 2014.

[6] O. Çerezci, B. Kanberoğlu, and Ş. Ç. Yener, "Analysis on trending electromagnetic exposure levels at homes and proximity next to base stations along three years in a city," J. Environ. Eng. Landsc. Manag., vol. 23, no. 1, pp. 71-81, 2015.

[7] IARC (2002) Monographs on the evaluation of carcinogenic risks to humans. Non-Ionizing Radiation, Part 1: Static and Extremely Low-Frequency (ELF) Electric and Magnetic Fields pages $429-436$, http://monographs.iarc.fr/ENG/Monographs/vol80/index.php.

[8] International Journal of Hygiene and Environmental Health Volume 210, Issue 5, 31 October 2007, Electromagnetic fields (EMF): Do they play a role in children's environmental health (CEH)? Pages 635-644.

[9] CIRC (2011) Le CIRC classe les champs électromagnétiques de radiofréquences comme "Peut-être cancérogène pour l'Homme» communique de presse 208 du 31 Mai 2011 http://www.iarc.fr/fr/media-centre/pr/2011/pdfs/pr208_F.pdf.

[10] Adama. Ly, «Ondes electromagnetiques, risques et cancers». Editorial Journal Africain du Cancer / Africain Journal of Cancer $\mathrm{N}^{\circ} 4$ (Novembre) Volume 6, 2014 sous presse.

[11] Avis de l'AFSSET, Rapport d'expertise collective. Les effets sanitaires des champs électromagnétiques extrêmement basses fréquences. Page 40 Edition scientifique, Agents physiques. Mars 2010.

[12] Mlle O. Tardy et M. R. LENNUIER. «Etude de l'influence d'un champ magnétique sur l'intensité des aies émises par quelques tubes à décharge». Laboratoire des recherches physiques de la Sorbonne. EDP Sciences sur http://dx.doi.org/10.1051/jphysap:0195800190707500. Juillet 1958.

[13] A. RAGHI. De l'influence du champ magnétique sur l'intensité du courant dans l'air raréfié. EDP Sciences et disponible sur http://dx.doi.org/10.1051/radium:01911008011041501 Janvier 1911.

[14] GUILLAUME GUERSAN, «Comment faire de l'économie des économies d'énergie sur ses postes de travail?» GreenIT. 27 Décembre 2017.

[15] Code de sécurité 6(2015), «Limites d'exposition humaine à l'énergie électromagnétique radioélectrique dans la gamme de fréquences de $3 \mathrm{KHz}$ à 300 Ghz». Le Bureau de la protection contre les rayonnements des produits cliniques et de consommation, Santé canada. 